\title{
A STUDY OF ANATOMICAL VARIATION IN BRANCHING PATTERN
} OF AXILLARY ARTERY

\author{
Gadekar S.H ${ }^{1}$, Rakate N.S ${ }^{*}$, Dhoot M.B ${ }^{3}$, Gajbhiye V.M ${ }^{4}$, Gadekar H.B ${ }^{5}$.
}

${ }^{1}$ Associate Professor, Department of Anatomy,RKDF Medical College Hospital \& Research Centre, Jatkhedi, Bhopal, Madhya Pradesh, India.

${ }^{2}$ Assistant professor, Department of Anatomy,RKDF Medical College Hospital \& Research Centre, Jatkhedi, Bhopal, Madhya Pradesh, India.

${ }^{3}$ Assistant professor, Department of Anatomy,RKDF Medical College Hospital \& Research Centre, Jatkhedi, Bhopal, Madhya Pradesh, India.

${ }^{4}$ Professor HOD Department of Anatomy,RKDF Medical College Hospital \& Research Centre, Jatkhedi, Bhopal, Madhya Pradesh, India.

${ }^{5}$ Professor HOD, Department of Microbiology, RKDF Medical College Hospital \& Research Centre , Jatkhedi, Bhopal, Madhya Pradesh, India.

\section{ABSTRACT}

Background: The axillary artery is a direct continuation of the subclavian artery. The axillary artery is usually gives off six branches. Variation in the branching pattern of axillary artery is very commonly seen. The knowledge in variations of axillary artery is helpful in anatomy, radiology and surgery to explain unexpected clinical signs and symptoms.

Materials and Methods: The present study undertaken on 30 upper limb (15 cadevers) in department of Anatomy at RKDFMCH\&RC, Jatkhedi, Bhopal. None of them had any pathological lesions, traumatic lesions or surgical procedures in the axillary region. Bilateral dissection of axilla was conducted and the branching patterns of the axillary artery was studied.

Observations and Results: Unilateral variations were observed in two cadavers. In $(6.66 \%)$ cases we observed a unique variation of early division of axillary artey. In (3.33\%) cases the second part of axillary artery shows three extra branches (alar artery) In (3.33\%) we observed a subscapular artery arises from the second part of axillary artery. Up to $36 \%$ of it arises from a common trunk with posterior circumflex humeral artery. In (3.33 \%), bilaterally a common trunk from II part gave origin to anterior circumflex humeral, post circumflex humeral and subscapular artery. In $3.33 \%$ cases the circumflex scapular artery directly arises from the third part of axillary artery. In $6.66 \%$ cases the anterior circumflex is three in number.In the rest of the cadavers, axillary artery was normal in its course and distribution.

Conclusion: The detailed knowledge about anatomy of normal as well as variant axillary artery is very helpful for the surgeons and radiologists performing interventional surgery.

KEY WORDS: Axillary Artery, Vascular Variation, Pectoralis Minor, Common Trunk.

Address for Correspondence: Dr. Rakate Nilesh S, Assistant professor, Department of Anatomy,RKDF Medical College Hospital \& Research Centre, Jatkhedi, Bhopal, Madhya Pradesh, India. Contact number-9039226335 E-Mail: nilesh.rakate19@gmail.com

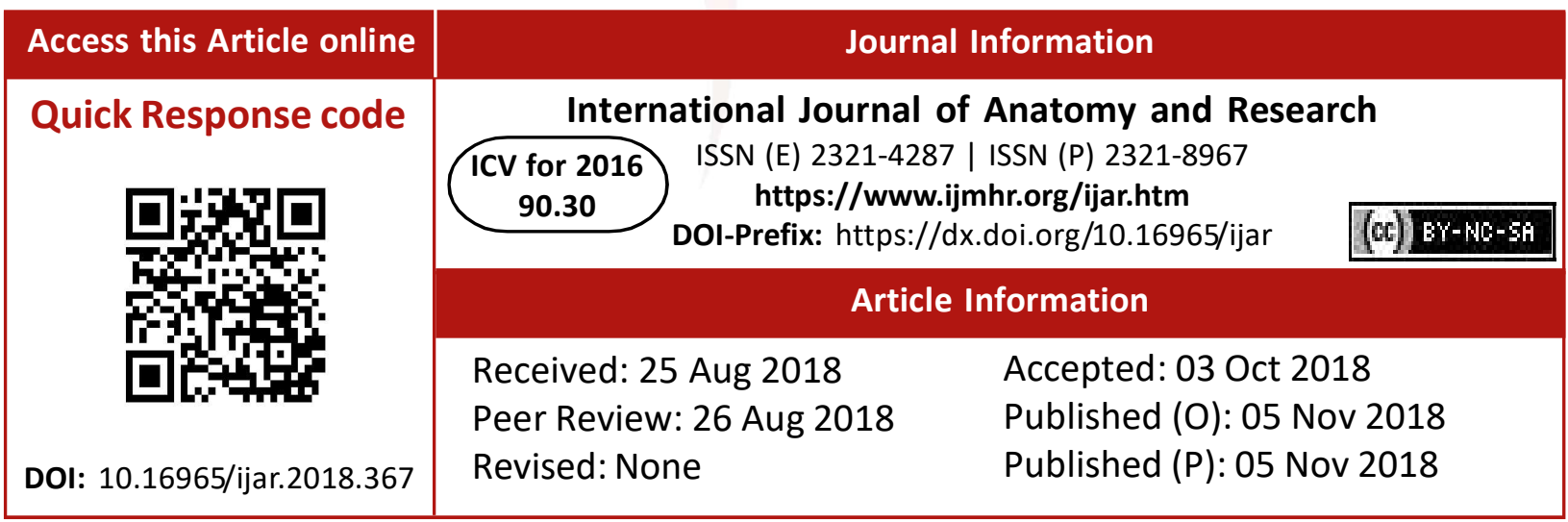




\section{INTRODUCTION}

Axillary artery is a continuation of the subclavian artery at the outer border of the first rib. The pectoralis minor muscle divides the axillary artery into three parts. The first part begins at the lateral border of the first rib and extends to the superomedial border of the pectoralis minor muscle. Along with the axiilary vein and brachial plexus first part of axillary artery is enclosed within the axillary sheath. The second part lies deep to pectoralis minor muscle and third part lies between the inferolateral border of the pectoralis minor and the inferior border of the teres major muscle [1]. The first part of the artery gives superior thoracic artery. The second part gives lateral thoracic and thoracoacromial artery. The third part gives subscapular artery, anterior and posterior circumflex humeral artery [2]. It is very com-mon to find the variations in the branching pattern of axillary artery. Knowledge of variations is important for orthopaedic surgeons as well as for vascular surgeons to avoid complications during various surgical procedures.

\section{MATERIALS AND METHODS}

The study was conducted at R.K.D.F. Medical College, Bhopal (M.P.) in 30 Upper Limbs of 15 adult ca-davers ( 9 males and 6 females). Dissection of pectoral, axillary region, arm and forearm was done according to the steps described in Cunningham's manual of practi-cal anatomy [3]. Skin and superficial fascia were removed then pectoralis major and pectoralis minor muscles with clavi-pectoral fascia were cleaned and separated. Further in dissection of axilla, axillary artery was cleaned and studied.

Observations: All the branches of three parts of axil-lary artery were dissected carefully and their relations with brachial plexus were studied. Variations in the branching pattern arising from three parts of axillary ar-tery were recorded and photographed. Normal branch-ing pattern was observed in about 22 upper limbs (73.33\%). In 3 upper limbs (10\%) variation in branching pattern was observed at II part of the axillary artery, while in another 5 up-per limbs (16.66\%) branching pattern variations were ob-served in III part.
Thirty specimen of superior extremity were dissected carefully and observation and results were described under following heading:

1) Variations in first part of axillary artery: In the present study we have not observed any variation in branching pattern of axillary artery.

2) Variations in second part of axillary artery: In the present study we have observed $10 \%$ variation at the second part of axillary artery.

They are as follow:

a) In one right upper limb (3.33\%) the second part of axillary artery show three extra branches. The extra branches coming from second part of axillary artery called as Alar arteries [1].

b) In one right upper limb (3.33\%), a common trunk from II part gave origin to anterior circumflex humeral, post circumflex humeral and subscapular artery but the profunda brachii artery was absent.

c) In one left upper limb (3.33\%) subscapular artery arises from the second part of axillary artery

3) Variations in the third part of axillary artery: Present study shows that the third part of axillary artery having $20 \%$ variations. They are as follow:

A) In two right upper limb (6.66\%) axillary artery dividing into radial artery and ulnar artery at the level of insertion of corachobrachia-lis. Instead of continuing as a brachial artery.(fig.1)

Fig.1: Showing axillary artery dividing into two branches.

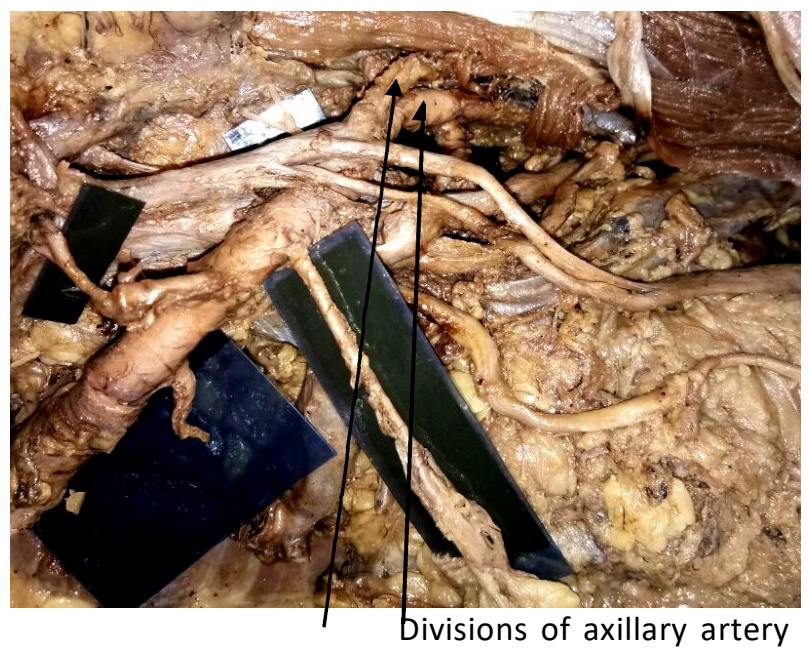

B) In left upper limb (3.33\%) Anterior and posterior circumflex humeral arteries and subscapular arteries were originating from a common trunk from III part. Fig.2 
Fig. 2: Showing common trunk for ant \& post circumflex scapular with subscapular arteries.

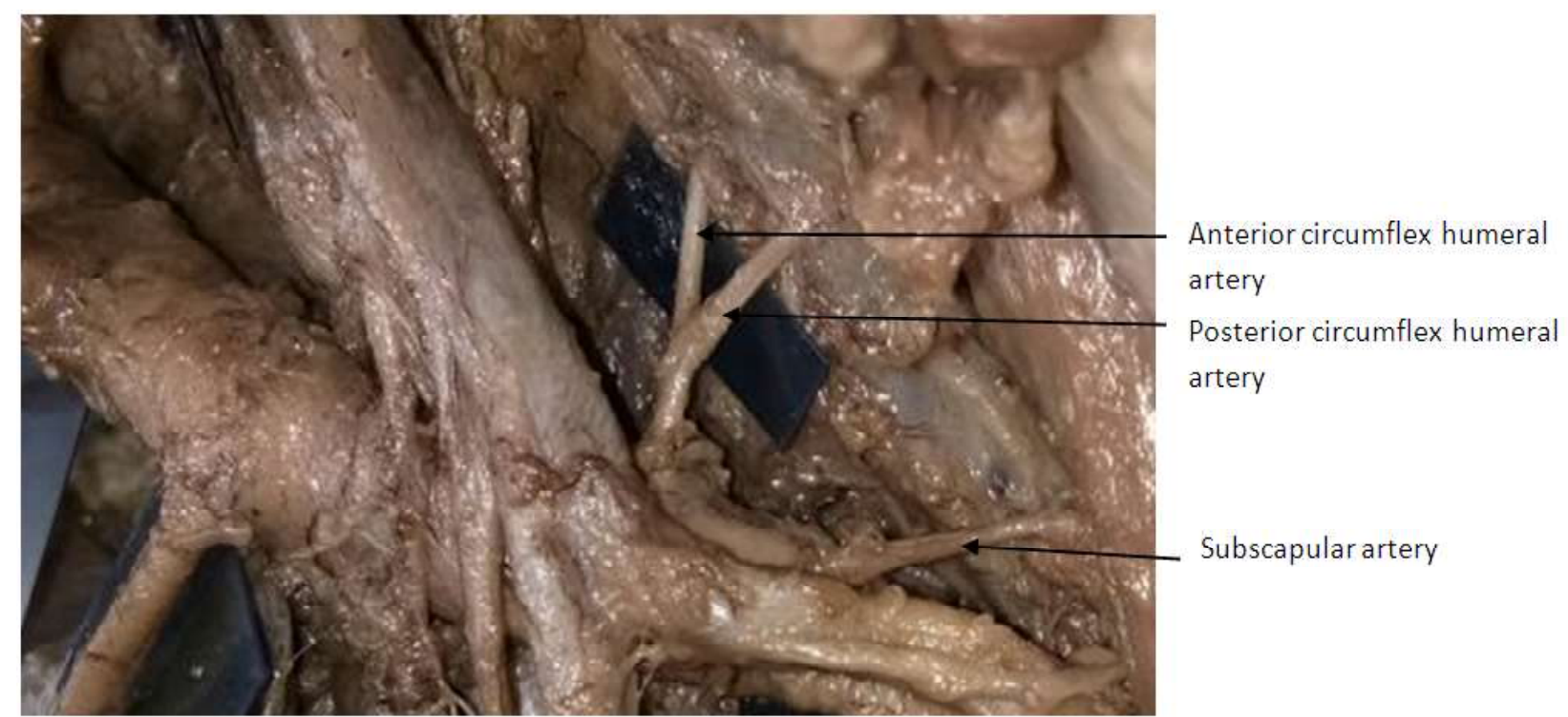

a) In one right upper limb (3.33\%) the circumflex scapular artery directly arises from the third part of axillary artery

b) In one right upper limb (3.33\%) the anterior circumflex is three in number.Fig.3

Fig. 3: Showing three anterior circumflex arteries.

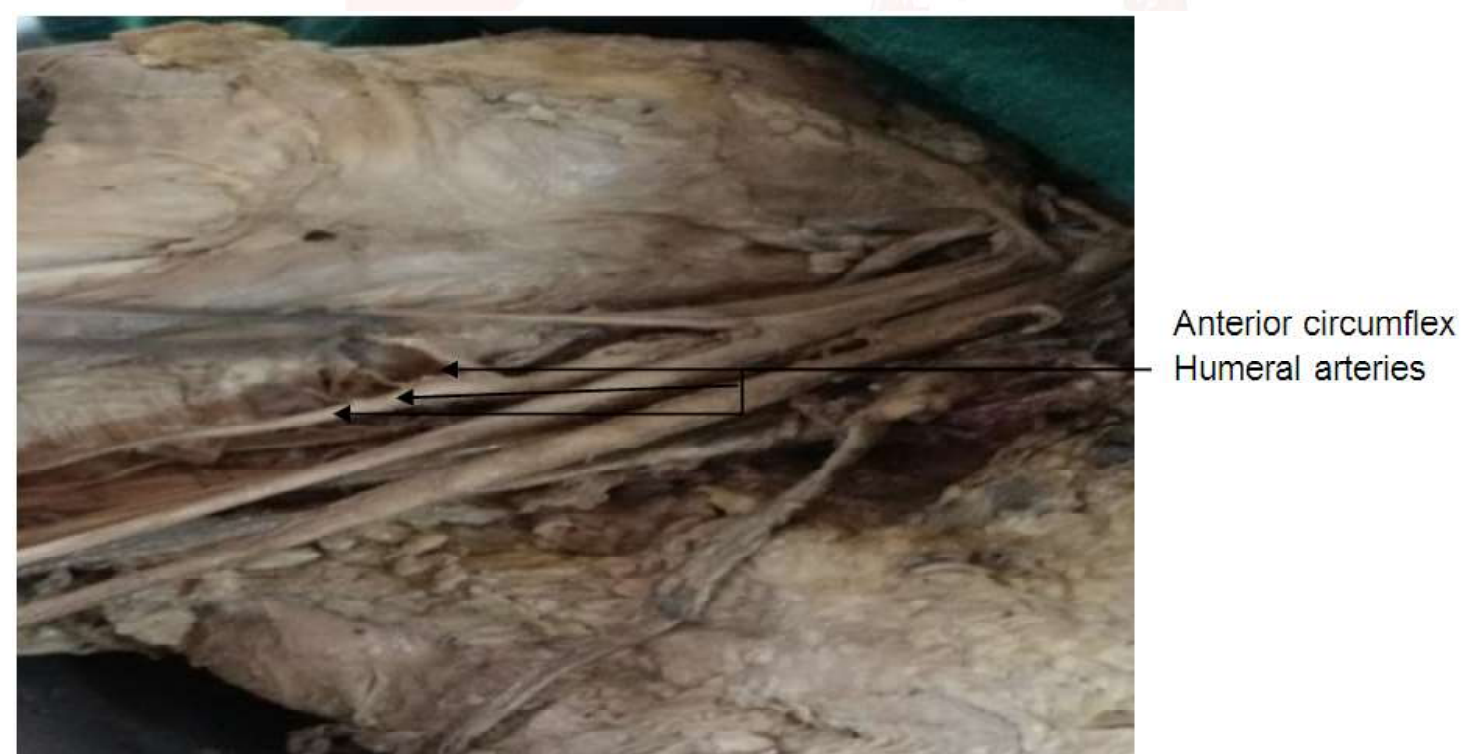

Variations in the axillary artery at origin, course and branching patterns are not frequent. During development the lateral branch of $7^{\text {th }}$ cervical inter segmental artery get enlarged to become the axial artery of upper limb which on further development form axillary, brachial and its bud gives rise to radial and ulnar arteries [4-6].

The arterial anomalies in the upper limb are due to defects in embryonic development of the vascular plexus in the upper limb buds. This may be due to arrest at any stage of development of the vascular plexus showing regression, retention or reappearance and may lead to variations in the arterial origins and courses of the major upper limb vessels [7].

The axillary artery usually gives off six branches but the number varies because two or more branches often arise together instead of arising separately or from the common trunk. Thus instead of six there may be 5-11 branches commonly seen in most cases. Around 5 to 11 branches arising from axillary artery found in the study of De Garis and Swartely [8].

Heulke [9], in his study, found 2 to 7 branches that arises directly from the axillary artery. Kanaka[10]etal. in their study observed 5-8 branches coming from axillary artery. In the 
present study, we found two-three branches coming from $2^{\text {nd }}$ part of axillary artery. So instead of six branches we found total 9 branches.

In $6 \%$ cases the 2 nd part of axillary artery gives extra branches they are reported as Alar branches by present study. Case with this kind of variation should be examine or operated carefully during surgeries involved in breast augmentation and mastectomy.

A rare anomaly arises when instead of continuing as a single brachial artery, the axiliary artery divides in the axilla into two branches. On entering the arm, one of the branches usually runs more superficially and may represent the radial or ulnar arteries, the deeper branch usually correspond to the brachial artery proper 6. In our observation also two right upper limb (6.66\%) axillary artery instead of continue as brachial artery, it gives early division of Axillary artery divided into radial artery and ulnar artery at the level of insertion of corachobrachia-lis.

The axillary artery bifurcated into almost equal size trunks. The superficial one continued as the brachial artery. The deep trunk divided into a common circumflex humeral-subscapular trunk and a profunda brachii artery. The common circumflex humeral subscapular trunk further divided to give anterior and posterior circumflex humeral arteries and subscapular artery [11]. In our study, we have found subscapular artery arising from 2 nd parts of axillary artery in $3.33 \%$ cases . In up to $30 \%$ of cases subscapular artery can arise from .Common trunk originating from second and third part of axillary artery has been reported in literature Saeed et al. [12] has reported a common subscapular-circumflex humeral trunk from the third part of axillary artery, which divided into subscapular, anterior circumflex humeral, and posterior circumflex humeral arteries in $3.8 \%$ of cases. Vijaya et al. [13] reported a common trunk from the third part of the axillary artery which gave origin to anterior circumflex humeral, posterior circumflex humeral, subscapular, radial collateral, middle collateral, and superior ulnar collateral arteries with absent profunda brachial artery. In our study in $3.33 \%$ cases Anterior and posterior circumflex humeral arteries and subscapular arteries were originating from a common trunk from III part. Bhat et al. [14] reported a case in which the common trunk gave rise to many branches such as the thoraco-acromial artery, the lateral thoracic artery, posterior circumflex humeral artery and sub scapular artery. The anterior circumflex humeral artery was found to arise from the third part. Chitra et al. [15] reported a common trunk for all the branches of II and III part of artery was no-ticed.

Number of variations in branching pattern of axil-lary artery is reported by different workers. Gaur S et.al[16] have reported the variations in branching pat-tern about $28 \%$ of cases and in $3.33 \%$ cases they observed two anerior circumflex humeral artery. We observed variations in the branching pattern about $26.66 \%$ of the cases we also observed three anterior circumflex humeral artery in $3.33 \%$ cases. Variations in the branching pattern of II \& III part is the most frequently noted in our study.

Taking into account the frequency of variations in the branching pattern of axil-lary artery is important for the orthopedician and vas-cular surgeons to know these anomalies to avoid complications during the surgical interventions.

\section{CONCLUSION}

In our routine dissection we observed variations in branching pattern of axillary artery. We have found variations in $26.66 \%$ of cases. Most of the variations are noticed in II \& III part of axillary artery but we have not observed any variation in Ist part of the artery. Knowledge of variations in the branching pattern of axil-lary artery is important for the orthopedician and vas-cular surgeons to know these anomalies to avoid complications during the surgical interventions.

\section{Conflicts of Interests: None}

\section{REFERENCES}

[1]. Standring S editor. Gray's Anatomy: The Anatomical Basis of Clinical Practice. 40th ed. 2008. ChurchillLivingstone: Elsevier. ISBN 978-0-443- 06684-89.

[2]. Snell R. Clinical Anatomy for medical students. 7th ed. 2004;475-477.

[3]. Romanes G J: Cunningham's Manual of Practical Anatomy. Vol 1 Upper Limb and Lower Limb 15th edi 2003;27-35.

[4]. Hamilton WJ, Mossman HW. In Cardiovascular system. Hu-man embryology. $4^{\text {th }}$ Edn, Williams and Wilkins, Baltimore 1972;pp.271-290. 
[5]. Tan C B, Tan C K. An unusual course and relations of the human axillary. Singapore Med J 1994; 35: 263264.

[6]. Jurjus AR, Correa-De-Aruaujo R, Bohn RC. Bilateral double axillary artery: embryological basis and clinical implications. Clin Anat 1999; 12:135-140.

[7]. Hamilton WJ, Mossman HW. Cardiovascular system. In: Human embryology. 4th ed. Baltimore: Williams and Wilkins, 1972; 271-290.

[8]. De Garis C.F. and Swartely W.B. The Axillary Artery in White and Negro Stocks. The American Journal of Anatomy.1928:41;353-397.

[9]. Huelke DF. Variation in the origins of the branches of the axillary artery. Anat Rec, 1959;135:33-41.

[10].Kanaka S, Eluru RT, Basha MA, Somasekhar R, Kanchanalatha G, Haniman KS. Frequency of variations in axillary artery branches and its surgical importance. Int J Sci Stud, 2015;3(6):1-4.

[11]. George, B. M.; Nayak, S. \& Kumar, P. Clinically significant neurovascular variations in the axilla and the arm - a case report.. Boston; Little Brown Co. Neuroanatomy, .; 1992;6(1):36-38.
[12]. Saeed M, Rufai AA, Elsayed SE, Sadiq MS. Variations in the subclavianaxillary arterial system. Saudi Med J, 2002;22:206-212.

[13]. Vijaya PS, Venkata RV, Satheesha N, Mohandas R, Sreenivasa RB, Narendra P. A rare variation in the branching pattern of the axillary artery.Indian J Plast Surg .2006;39:222-3.

[14]. Bhat KM, Gowda S, Potu BK, Rao MS. A Unique branching pattern of the axillary artery in a South Indian male cadaver. Bratisl Lek Listy, 2008;109:587-589.

[15]. Chitra P.S.,Anandhin.V. A Unique variation in branching pattern of axillary artery.International Journal Of Anatomi-cal Variations . $2013 ; 6: 1-3$.

[16]. Gaur S, Katariya S, Vaishnani H, Wani NI, Bondre KV, Shah G V. A Cadaveric Study of Branching Pattern of the Axillary Artery Int J Biol Med Res. 2012; 3(1):1388-1391.

\author{
How to cite this article: \\ Gadekar S.H, Rakate N.S, Dhoot M.B, Gajbhiye V.M, Gadekar H.B. \\ A STUDY OF ANATOMICAL VARIATION IN BRANCHING PATTERN \\ OF AXILLARY ARTERY. Int J Anat Res 2018;6(4.2):5883-5887. DOI: \\ 10.16965/ijar.2018.367
}

